REVISTA DE CIENCIAS AGRÍCOLAS

Volumen 31 (2): 3 - 13

Segundo Semestre

ISSN Impreso 0120-0135

\title{
TÓXIDAD DE CADMIO Y PLOMO EN PASTO TANNER Brachiaria arrecta
}

\section{CADMIUM AND LEAD TOXICITY IN TANNER GRASS Brachiaria arrecta}

\author{
Manuel Peláez P. ; Fanor Casierra-Posada. ${ }^{2}$; Gerardo A. Torres R.;
}

Fecha de recepción: Agosto 18 de 2014 Fecha de aceptación: Noviembre 05 de 2014

\section{RESUMEN}

Se evaluó fisiopatías en Brachiaria arrecta expuestas a contenidos tóxicos de cadmio y plomo en el invernadero de la Universidad Nacional de Colombia Sede Palmira, se doparon plántulas sanas de 20 días de edad bajo cultivo hidropónico. El objetivo fue describir síntomas crecientes por intoxicación con el diseño de una escala valorativa de daños crecientes, adicionalmente se evaluaron cambios histológicos de raíz tallo y hojas mediante microscopia de luz de alta resolución (MLAR). Las plantas fueron sometidas a estrés abiótico con los tratamientos de sales de $\mathrm{CdCl}_{2}$ en concentración de 10 ppm, y de $\mathrm{Pb}\left(\mathrm{NO}_{3}\right)_{2} 500$ ppm, respectivamente. Los resultados principales mostraron un mayor detrimento cuando las plantas fueron expuestas al metal plomo que al cadmio en las raíces, tallos y hojas. Se apreciaron deformaciones extremas en paredes celulares de las células del cortex y en la endodermis de la raíz; en las hojas los daños fueron notorios para ambos metales sobre todo en el parénquima clorofílico y en la deformación de paredes de la epidermis tanto en haz como envés; en los tallos aparecieron deformaciones de las células del parénquima

1 Docente Tiempo Completo. Ph.D. Universidad de Pamplona, Pamplona, Norte de Santander, Colombia. manuelpelaez@unipamplona.edu.co

2 Docente Tiempo Completo. Ph.D. Universidad Tecnológica y Pedagógica de Colombia (UPTC), Tunja, Boyacá. Colombia. fanor. casierra@uptc.edu.co 
de relleno cuando ocurre bioacumulación intensa de plomo. Estos resultados sugieren que la bioconcentración en los tejidos vegetales ocasiona trastornos histológicos, que pueden involucrar una red trófica y por consiguiente consecuencias en la Salud Pública.

Palabras clave: Estrés abiótico, metales pesados, pasturas tropicales, Poáceas, contaminación antrópica.

\begin{abstract}
Physiopathologies in Brachiaria arrecta exposed to toxic contents of cadmium and lead were evaluatedin healthy 20-day old seedlings under hydroponic growth in the greenhouse of the Universidad Nacional of Colombia at Palmira. The study aimed to describe increasing symptoms due to poisoning, through the design of a rating scale of increasing damage. In addition, histological changes in roots, stems, and leaves were evaluated by high resolution light microscopy (HLRM). In this regard, the plant material was subjected to abiotic stress treatments with $\mathrm{CdCl}_{2}$ salts at $10 \mathrm{ppm}$ concentration and $\mathrm{Pb}\left(\mathrm{NO}_{3}\right)_{2}$ salts at $500 \mathrm{ppm}$. The main results showed greater deterioration in roots, stems, and leaves when plants were exposed to lead rather than cadmium. Extreme deformities were observed in cell walls of cortex cells and in the endodermis of the root. Leaf damage was notorious for both metals, especially in the chlorophyll parenchyma and in the deformity of epidermal walls of the adaxial and abaxial sides of the leaf. Deformities in the stems appeared in parenchymal filler cells with intense lead bioaccumulation. These results suggest that bioconcentration in plant tissues causes histological disorders, which may involve a food web, therefore, impacting on public health.
\end{abstract}

Keywords: abiotic stress, heavy metals, tropical pastures, grasses, anthropogenic pollution.

\section{INTRODUCCIÓN}

La epidemiología agrícola, ha demostrado una estrecha analogía entre los factores de riesgo ambiental y predisposición a enfermedad en una población vegetal, por un estrés abiótico (Porta, 2008), entre estos, la presencia de un metal pesado sin funcionalidad biológica y que altera la fisiología de la planta y que tiene consecuencias sobre la morbilidad, en razón de la casuística de los procesos de salud en los agroecosistemas (endemismos multiplex) (Bhopal, 2008). En tal sentido, la misma epidemiología puede extenderse al estudio y cuantificación de la presencia y efectos de éstos factores de predisposición, a epidemias en una población vegetal y sus repercusiones sobre las redes tróficas y la salud pública, en programas de vigilancia epidemiológica, definida como un servicio de importancia cuyo fin sea decidir con bases objetivas o científicas, sobre acciones en el tiempo a fin de controlar o prevenir un problema de salud evidente (Romero et al., 2007).

Las poblaciones vegetales de Brachiaria spp. han sido mejoradas y liberadas por los sistemas de disciplinas de mejoramiento genético de centros de investigación tanto nacionales como 
internacionales, por sus excelentes cualidades forrajeras como tolerancia a estreses abióticos entre otros: las sequias, las bajas fertilizaciones, los suelos ácidos y los excesos de humedad (Canchila et al., 2010). Sin embargo, hay un vacío en el conocimiento relacionado con estrés por presencia y bioacumulación de metales pesados tóxicos en estos agroecosistemas forrajeros, a nivel de trópico, cuando existe un factor predisponente como es una actividad antropogénica.

En la actualidad, los metales pesados tienen un gran significado como indicadores de la calidad ecológica de los suelos debido a su toxicidad y muy especialmente del comportamiento bioacumulativo en agroecosistemas (Sánchez et al., 2007; Cobb et al., 2009). La acción de los metales es de gran importancia debido a su propiedad de bioacumulación, toxicidad y efectos directos sobrela salud en todo tipo de sistemasvivos, en las relaciones suelo-agua-planta y sobre ser humano (Weng et al., 2001). En el trópico es muy reconocida, la tolerancia de forrajes como las especies de Brachiaria. Olivera et al. (2009), explica que estas poaceae poseen una capacidad amplia de adaptación a los ambientes rústicos, lo que redunda en ciertas características agronómicas, como son: la producción de hojas y pequeños rizomas que facilitan la emergencia de los tallos, su tasa de crecimiento y su alta capacidad para la producción de forraje en condiciones estresantes.

En éste trabajo, se evalúa el grado de respuesta de los tejidos vegetales de plantas Brachiaria arrecta, (Poaceae) expuestas a concentraciones altas de dos metales pesados como Cadmio y Plomo, y de ésta forma identificar daños a nivel histológico y la relación con los cambios anatómicos bajo estrés inducido.

\section{MATERIALES Y MÉTODOS}

El material vegetal se obtuvo a partir de la recolección de plantas de Brachiaria arrecta (DUR Y SCHINZ) STENT., en Casabe municipio de Yondó, Antioquía (N 7.039775, W -73.918277) y el campo de refinería de Ecopetrol en el corregimiento del Centro en Barrancabermeja ( $\mathrm{N}$ 6.937722, W-73.761419) en el Magdalena Medio Colombiano. Con el material vegetal recolectado se realizaron las accesiones correspondientes y se creó un banco de plantas madre. Una vez que se obtuvo las plántulas de 20 días, propagadas en turba para lograr un enraizamiento vigoroso, como etapa previa al establecimiento del cultivo hidropónico, siguiendo la metodología de Shannon et al, (2010), de la Universidad deMissouri-Culumbia con modificaciones, consistentes en cultivo hidropónico, utilizando vasos de 120 cc como contenedores rellenos con arenas de Cuarzo o Sílice (Contenido de $\mathrm{SiO}_{2}$ de mínimo 95\%), los cuales se ubicaron en una bandeja de vidrio con 6 vasos sumergidos en la solución nutritiva de Hoagland con la siguiente composición de sales: $0,20 \mathrm{M} \mathrm{NH}_{4} \mathrm{H}_{2} \mathrm{PO}_{4^{\prime}} 0,50 \mathrm{M} \mathrm{NH}_{4} \mathrm{NO}_{3^{\prime}}, 1,15 \mathrm{M}$ $\mathrm{Ca}\left(\mathrm{NO}_{3}\right)_{2}, 0,26 \mathrm{M} \mathrm{CaCl}, 0,20 \mathrm{M} \mathrm{MgCl} \cdot 6 \mathrm{H}_{2} \mathrm{O}$, $0,20 \mathrm{M} \mathrm{Mg}\left(\mathrm{NO}_{3}\right)_{2} \cdot 6 \mathrm{H}_{2} \mathrm{O}, 0,40 \mathrm{M} \mathrm{MgSO}{ }_{4} 7 \mathrm{H}_{2} \mathrm{O}$, $0,20 \mathrm{M} \mathrm{KH} \mathrm{PO}_{4^{\prime}}, 1,20 \mathrm{M} \mathrm{KNO}_{3^{\prime}}, 0,50 \mathrm{M} \mathrm{K} \mathrm{SO}_{4^{\prime}}$ $0,040 \mathrm{M} \mathrm{FeCl}_{3} \cdot 6 \mathrm{H}_{2} \mathrm{O}, 1,2 \times 10^{-2} \mathrm{M} \mathrm{H}_{3} \mathrm{BO}_{3^{\prime}} 1,2 \times 10^{-}$ ${ }^{4} \mathrm{M} \mathrm{CuCl}_{2} \cdot \mathrm{H}_{2} \mathrm{O}, 2,3 \times 10^{-3} \mathrm{M} \mathrm{ZnCl}_{2^{\prime}} 4,4 \times 10^{-4} \mathrm{M}$ $\mathrm{MnCl}_{2} \cdot 4 \mathrm{H}_{2} \mathrm{O}, 6 \times 10^{-6} \mathrm{M} \mathrm{Na}_{2} \mathrm{MoO}_{4} \cdot \mathrm{H}_{2} \mathrm{O}$, EDTA y $\mathrm{FeSO}_{4} \cdot 7 \mathrm{H}_{2} \mathrm{O}$, con un $\mathrm{pH}=6$ (Resh,2001).

\section{Observaciones fisiopáticas}

Los análisis fisiopáticos macro, correspondieron a evaluar y confirmar respuestas a daños inducidos como: resistencia, susceptibilidad o tolerancia (respuesta en términos de recuperación de las accesiones evaluadas de $B$. arrecta, las plantas fueron sometidas a estrés por dopaje con concentraciones anómalos de éstos 
dos metales pesados en sales (Tab.1), aplicado en drenchs sobre los cuellos en los tallos de las plántulas que reposaban en el sustrato compuesto por arenas de cuarzo, siguiendo la metodología de Brown y Hock (1988). Las concentraciones en los sustratos, se hicieron con base a los criterios internacionales; se tomaron niveles de $\mathrm{Cd}$ a 10 ppm y para plomo de 500 ppm, que están dentro de los rangos de niveles tóxicos en plantas cultivadas para suelos contaminados, según Bowie y Thornston (1985), como anormal hasta 30 ppm. Para plomo como anormal hasta $\geq 720$ ppm.

Las observaciones sobre los daños fitotóxicos inducidos por los tratamientos, fueron evaluados siguiendo una escala de reacciones crecientes, diseñada y propuesta por los investigadores, ante la ausencia de otras escalas como parámetros de comparación, fruto de otras investigaciones de este tipo, donde se tuvieran en cuenta interacciones planta-patógeno (abiótico) o disturbio fisiológico por el estrés metalífero en pasturas de trópico, especialmente agroecosistemas de Brachiaria.

\section{Procesamiento de muestras para Microscopia de Luz de alta resolución}

Se recolectaron tejidos de raíces, tallo y hoja de plantas expuestas y un testigo. Las muestras se procesaron con "resina Spurr" (Mercer y Birberk, 1974) en tamaños de $1 \mathrm{~mm}$ de grosor las cuales se fijaron en glutaraldehido al $2 \%$ por 8 horas; se realizaron dos lavados con buffer fosfato $0,1 \mathrm{M}$ con un $\mathrm{pH}$ de 7,2 , se posfijaron con tetraóxido de osmio al $1 \%$ a temperatura ambiente durante 2 horas, seguido tres veces con agua destilada. La deshidratación se realizó con etanol en concentraciones de 20, 30, 40, $50,60,70,80,90$, y dos repeticiones al $100 \%$ por un periodo de 15 minutos por cada cambio, se realizó pre imbibición en acetona pura tres veces por 20 minutos, la inclusión fue 1:1 con resina Spurr y acetona durante 1 hora. Posteriormente se embebió dos veces en resina pura por un periodo de 1 hora se polimerizó a $60^{\circ} \mathrm{C}$ por 48 horas. Se realizaron cortes semifijos de 300 (nm) nanómetros de grosor en ultramicrotomo RCM XL y se colorearon con azul de toluidina al $2 \%$; las micrografías se tomaron en la Unidad de Microscopia Electrónica de la Universidad del Cauca en un microscopio de luz Nikon $80 \mathrm{i}$ a 4,10 y $40 \mathrm{X}$.

\section{RESULTADOS Y DISCUSIÓN}

El conocimiento del mecanismo de acción de las contaminantes xenobióticos como el cadmio y el plomo y su acción tóxica sobre los tejidos fundamentales de ésta Poaceae ampliamente cultivada

Tabla 1. Tratamientos utilizados para evaluar la toxicidad de Cadmio y Plomo en pasto tanner Brachiaria arrecta

\begin{tabular}{c|c|c|c}
\hline Tratamientos & Notación & $\begin{array}{c}\text { Nivel en } \\
\text { sustrato } \\
\text { arena cuarzo }\end{array}$ & $\begin{array}{c}\text { Concentración } \\
\mathbf{p p m} \text { ó (mg/kg) }\end{array}$ \\
\hline 1 & Cd alto & anómalo & $10 \mathrm{ppm}$ \\
\hline 2 & $\mathrm{~Pb}$ alto & anómalo & $500 \mathrm{ppm}$ \\
\hline 3 & $\begin{array}{c}\text { Testigo } \\
\text { (blanco) }\end{array}$ & & $\begin{array}{c}\text { solución nutritiva de } \\
\text { Hoagland, M.P. }\end{array}$ \\
\hline
\end{tabular}


en zonas expuestas a la contaminación antrópica como la minería o la explotación de crudo (Sánchez et al., 2007), ha permitido no sólo definir sus particularidades estructurales, sino comprender los procesos de bloqueo de las funciones vitales de esta pastura de trópico bajo y sus canales de interconexión como los de $\mathrm{Ca}^{2+} \mathrm{y}$ la bioacumulación y eliminación de estos contaminantes. En la tabla 2 se describe la escala de reacciones crecientes por toxicidad de metales pesados y la reacción de la pastura ante el estrés abiótico.

Tabla 2. Escala de Estadios crecientes por toxicidad de metales pesados Cadmio y Plomo en Brachiaria arrecta (Hack. ex T. Durand \& Schinz) (Peláez, 2014)

\begin{tabular}{|c|c|c|c|c|}
\hline Estadio & Denotación & $\begin{array}{c}\text { Descripción } \\
\text { Marcador de daño }\end{array}$ & $\begin{array}{c}\text { Reacción de la } \\
\text { Planta ante el } \\
\text { metal pesado }\end{array}$ & $\begin{array}{c}\text { Situación de respuesta } \\
\text { de la planta }\end{array}$ \\
\hline 1 & $\begin{array}{c}\text { SD } \\
\text { Sin daño }\end{array}$ & $\begin{array}{l}\text { Sin daño (SD): el tejido se encuentra apa- } \\
\text { rentemente sano, sin deterioro en ambos } \\
\text { limbos foliares, las raíces están turgentes, } \\
\text { abundantes y de color blanco o cremoso }\end{array}$ & $\begin{array}{c}\mathrm{T} \\
\text { Tolerante }\end{array}$ & $\begin{array}{l}\text { Tolerante (T). La planta es resistente ante la } \\
\text { presencia del metal pesado en sus tejidos, aun- } \\
\text { que lo esté bioacumulando, posiblemente en las } \\
\text { raíces o en estructuras aéreas bajas. }\end{array}$ \\
\hline 2 & Daño Leve & $\begin{array}{l}\text { Daño leve (DL): Las hojas muestran lige- } \\
\text { ras quemaduras en las puntas, sin pérdida } \\
\text { severa del color verde; las raíces poco } \\
\text { abundantes, color pardo. La planta puede } \\
\text { recuperarse. }\end{array}$ & $\begin{array}{l}\text { (LR) Ligeramente } \\
\text { Tolerante }\end{array}$ & $\begin{array}{l}\text { Ligeramente tolerante (LT). La planta puede } \\
\text { llegar a tener contacto con el metal pesado, lo } \\
\text { puede absorber, transportarlo y concentrarlo en } \\
\text { sus tejidos, manifestar toxicidad de leve a muy } \\
\text { leve y rápidamente recuperarse ante el estrés } \\
\text { del xenobiótico eliminándolo por exclusión. }\end{array}$ \\
\hline 3 & $\begin{array}{c}\text { DM } \\
\text { Daño } \\
\text { moderado }\end{array}$ & $\begin{array}{l}\text { Daño moderado (DM): Las hojas pierden } \\
\text { turgencia, puede presentarse una ligera } \\
\text { clorosis. Entre un } 25 \% \text { y } 50 \% \text { de las raíces } \\
\text { no son funcionales, su color es pardo rojizo } \\
\text { muy intenso. La planta puede recuperarse. }\end{array}$ & $\begin{array}{l}\text { (MR) Moderada- } \\
\text { mente tolerante }\end{array}$ & $\begin{array}{l}\text { Moderadamente tolerante (MT). La planta } \\
\text { tolera cierto grado de acumulación y daño vi- } \\
\text { sible, manifestando una apariencia de disturbio } \\
\text { tóxico temporal. Los puntos de crecimiento } \\
\text { vegetativo no se afectan, presentando recupe- } \\
\text { ración durante el crecimiento ulterior a la in- } \\
\text { toxicación por el metal pesado. Sin embargo, } \\
\text { la bioacumulación y la bioconcentración pue- } \\
\text { den llegar a ser altas, pero sin manifestación de } \\
\text { daño total. }\end{array}$ \\
\hline 4 & $\begin{array}{c}\text { DS } \\
\text { Daño severo }\end{array}$ & $\begin{array}{l}\text { Daño severo (DS): Hay una clorosis ge- } \\
\text { neralizada en las hojas, crecimiento di- } \\
\text { latado en las hojas nuevas. A su vez, las } \\
\text { hojas jóvenes aparecen enrolladas. Las } \\
\text { hojas también pueden dar un aspecto de } \\
\text { estar quebradizas o arrugadas. En algunas } \\
\text { hojas pueden aparecer estrías o un cribado } \\
\text { sobre las nervaduras. Las puntas aparecen } \\
\text { quemadas. Se puede presentar una necro- } \\
\text { sis prematura sobre las hojas bajeras. Las } \\
\text { raíces han perdido más del } 50 \% \text { de su fun- } \\
\text { cionalidad, puede perderse entre } 25 \% \text { Y } \\
50 \% \text { de raíces por necrosis avanzada, con } \\
\text { coloración rojiza o marrón intensa. }\end{array}$ & (S) Susceptible & $\begin{array}{l}\text { Susceptible (S). La planta es muy susceptible } \\
\text { ante la presencia del metal pesado, no es capaz } \\
\text { de reproducir nuevo tejido sin síntomas de toxi- } \\
\text { cidad, como clorosis, cribados. Los tejidos nue- } \\
\text { vos pierden turgencia. Por la bioacumulación o } \\
\text { bioconcentración la planta transpira, y no hace } \\
\text { fotosíntesis. Se detiene el crecimiento aéreo. }\end{array}$ \\
\hline 5 & $\begin{array}{c}\text { DE } \\
\text { Daño extremo }\end{array}$ & $\begin{array}{l}\text { Daño extremo (DE): Ocurre la muerte par- } \\
\text { cia o total de la planta. Presentando pérdida } \\
\text { de turgencia, seguida de necrosis seca en te- } \\
\text { jidos de hoja y de tallo, en algunos casos con } \\
\text { doblado de hojas y muerte de la hoja bande- } \\
\text { ra. Pérdida total de las raíces hasta un } 100 \% \text {. } \\
\text { La planta definitivamente muere al perder } \\
\text { su capacidad fotosintética y su sistema de } \\
\text { transporte de nutrientes. }\end{array}$ & $\begin{array}{l}\text { (MS) Muy } \\
\text { susceptible }\end{array}$ & $\begin{array}{l}\text { Muy susceptible (MS). La planta es muy sus- } \\
\text { ceptible ante la presencia del metal pesado, mos- } \\
\text { trando sensibilidad temprana ante el tóxico. Ocu- } \\
\text { rre muerte temprana ante el metal pesado. }\end{array}$ \\
\hline
\end{tabular}




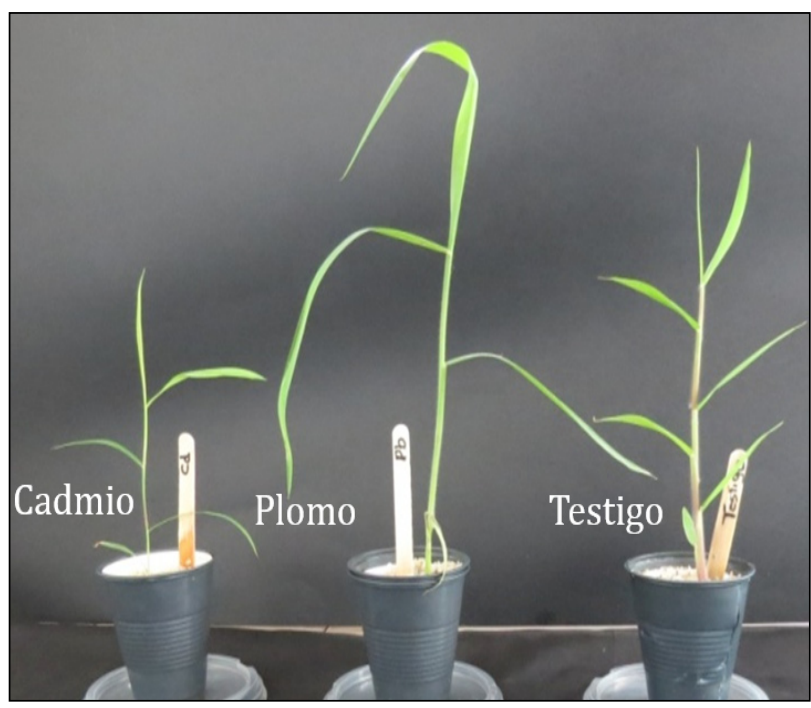

Figura 1. Aspectos generales del efecto macro de los tratamientos con cadmio y plomo en relación al testigo, en pasturas de B. arrecta

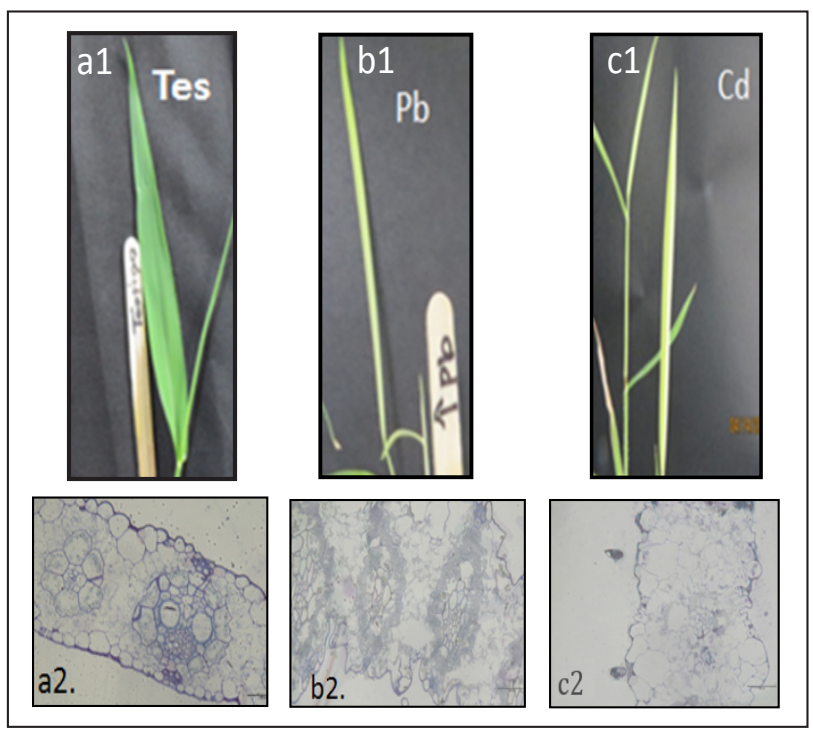

Figura 2. Síntomas macros de toxicidad con plomo y cadmio en hojas de $B$. arrecta en relación al testigo: a1 hoja testigo, a2. Corte transversal en la hoja testigo; b1 hoja intoxicada con plomo 500 ppm, b2. Corte transversal en la hoja tratada con plomo; c1 hoja intoxicada con cadmio 10 ppm, c2. Corte transversal en la hoja tratada con cadmio

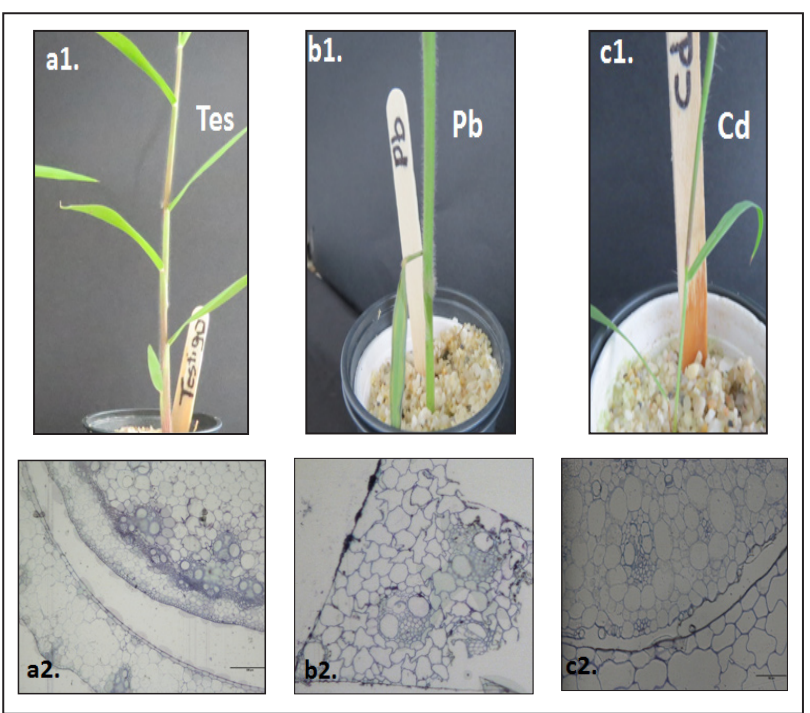

Figura 3. Síntomas macros de toxicidad por plomo y cadmio en tallos de B. arrecta en relación al testigo: a1 tallo testigo, a2. Corte transversal en el tallo testigo; b1 tallo intoxicado con plomo 500 ppm, b2. Corte transversal en el tallo tratada con plomo; c1 tallo intoxicado con cadmio $10 \mathrm{ppm}, \mathrm{c} 2$. Corte transversal en el tallo tratado con cadmio

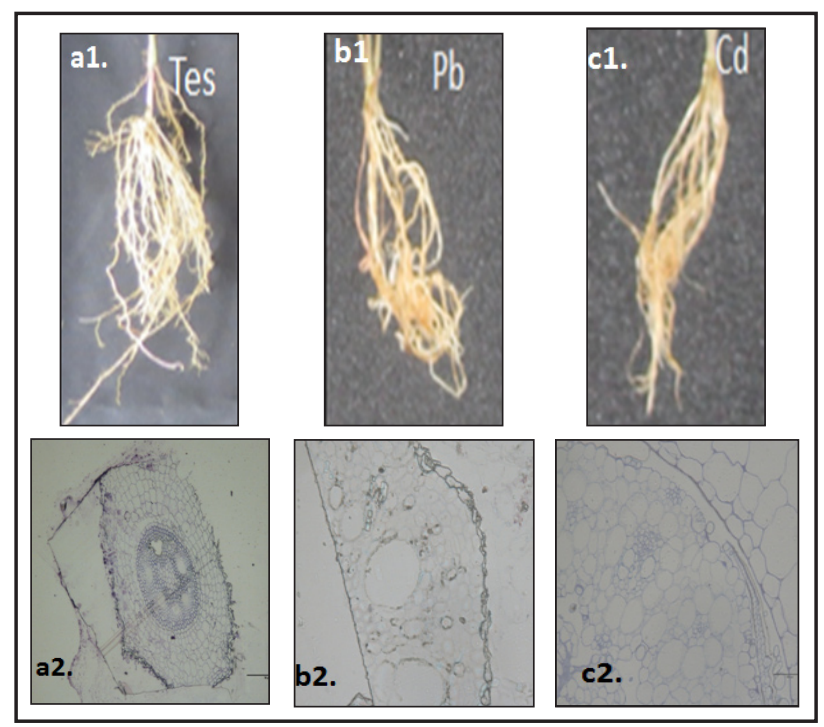

Figura 4. Síntomas macros de toxicidad por plomo y cadmio en raíces de $B$. arrecta en relación al testigo: a1 raíz testigo, a2. Corte transversal en raíz testigo; b1 raíz intoxicada con plomo 500 ppm, b2. Corte transversal en raíz tratada con plomo; c1 raíz intoxicada con cadmio 10 ppm, c2. Corte transversal en raíz tratada con cadmio. 
Se encontró el efecto deletéreo de éstos metales utilizados como dopaje en las sales que contenían los metales pesados $\mathrm{Cd}^{2+}$ a $10 \mathrm{ppm}$ y para $\mathrm{Pb}^{2+} \mathrm{de}$ $500 \mathrm{ppm}$, los cuales tienen un incremento que rebasa los límites máximos permisibles por la Norma Internacional para Alimentos Animales, para pasturas o forrajes no existen dichos límites (DOCE, 2001). Además, se buscó relacionar los daños fitotóxicos asociados a los daño de tejido ultraestructural (Fig. 2, 3 y 4). La técnica de microscopia de luz de alta resolución (MLAR), demostró ser efectiva en los bioensayos en cultivo hidropónico más el dopaje para evaluar ambos detrimentos en la pastura tropical.

El plomo y el cadmio son minerales que existen naturalmente en la corteza terrestre, además de que la agricultura y sobre todo las industrias como las explotaciones mineras (legal o ilegal) y las petroleras, los han diseminado a través del medio ambiente de muchas maneras formando compuestos como los óxidos de plomo, el tetraetilo de plomo, el sulfuro de cadmio, entre otros. Para el caso del plomo, éste puede entrar al ambiente a través de liberaciones desde minas de plomo y otros metales, desde fábricas que lo manufacturan, por aleaciones o compuestos de plomo. Las plantas de B. arrecta utilizadas en estos bioensayos crecen en estos ambientes, donde es liberado al aire cuando es quemado el petróleo en campos aledaños a la estatal petrolera ECOPETROL en el Magdalena Medio Colombiano, de donde se tomó éstas pasturas que mostraron fitotoxicidad debido al estrés (Peláez et al., 2014). Otra posible causa de la presencia de plomo en estos suelos, es que en el pasado reciente se utilizó plomo en la gasolina, lo cual es un contaminante latente, presentando los niveles más elevados de plomo que se encuentran cerca de carreteras de estos complejos petrolíferos (Nastar, 2012). En el caso del cadmio, las vías naturales y antropogénicas se reflejan en las emisiones industriales presentes en estas zonas y de la aplicación de fertilizantes y de las aguas superficiales con las que riegan éstos cultivos (Cheng et al., 2001).

Los bioensayos en invernadero, mostraron que el sistema hidropónico con la solución nutritiva de Hoagland más los tratamientos con las sales de $\mathrm{CdCl}_{2}$ y $\mathrm{Pb}\left(\mathrm{NO}_{3}\right)_{2}$, fueron efectivos con estas altas concentraciones de cadmio y plomo y que pueden provocar efectos citotóxicos que se manifiestan por la deformación de las paredes celulares de las células del cortex y en la endodermis de la raíz, posiblemente a que éste metal no es un elemento esencial para éstas plantas y que cuando este ión se pone en contacto con aire húmedo o agua, la reactividad aumenta en la superficie del plomo, formándose por consiguiente una pequeña capa de óxido de plomo $(\mathrm{PbO})$, en presencia de oxígeno y agua, y este se convierte en hidróxido de plomo $\left(\mathrm{Pb}(\mathrm{OH})_{2}\right)$ siendo así absorbido por las raíces de la planta, causando estrés iónico debido a su elevado índice de covalencia donde el catión libre $\mathrm{Pb}^{2+}$ suele ser la forma más fitotóxica (Siegel, 2002). Según Davies (1995), los factores que contribuyen a una elevada tasa de bioacumulación de éste metal en las raíces son la capacidad de intercambio catiónico en el suelo y en la planta la superficie de la raíz (Barceló et al., 2003), los exudados radicales, la micorrización y al tasa de transpiración (Marschner et al., 1996), lo cual se cumple para ésta investigación, justificado en las condiciones ambientales, fueron de temperaturas altas, con una media humedad relativa, la cual se vio compensada por el sistema de hidroponía.

La retención del plomo en las raíces, se fundamenta en la unión de $\mathrm{Pb}^{2+}$ hacia iones con sitios intercambiables sobre la pared celular formando 
depósitos en la misma, por consiguiente ocurre una precipitación extracelular a la forma de carbonato de plomo. Autores como Jarvis y Leung (2002), mencionan que el plomo se bioacumula mayormente en las raíces de las plantas más que en otra parte, debido a que el ion $\mathrm{Pb}^{2+}$ se une fuertemente a los grupos carboxilo del ácido galacturónico y al propio galacturónico que está presente en las paredes celulares y que restringe su transporte vía apoplasto. Espinoza et al. (2013), afirman que las plantas en general pueden absorber del suelo altos niveles de plomo hasta 500 ppm, que fue la concentración utilizada en el dopaje para esta investigación, mostrando daño fitotóxico y citotóxico lo que induce retardo en el crecimiento de la planta e inclusive la muerte en algunos casos como se vio en la descripción de síntomas crecientes (Tab. 2).

Huang y Cunnigham (1996), encontraron que cuando el plomo es transportado desde el suelo hacia las células de la raíces, traspasa la membrana plasmática de la epidermis y el cotex en las raíces. Huang et al. (1994), mencionan que este fenómeno quizás se deba a que el plomo se transporta por la membrana plasmática mediante canales catiónicos, como los del Calcio estos investigadores han caracterizado la funcionalidad de los canales de $\mathrm{Ca}^{+2}$ en trigo y maíz midiendo el voltaje por la dinámica de la actividad semipermeable de la membrana de la raíz. Huang y Cunningham (1996), mencionan que ocurre inhibición de los canales de $\mathrm{Ca}^{+2}$ por $\mathrm{Pb}^{2+}$ debido a un bloqueo del canal por el $\mathrm{Pb}^{2+}$, por competencia del $\mathrm{Pb}^{2+}$ a través de $\mathrm{Ca}^{2+}$. Ahora al estar bloqueados los canales de calcio se presentara apoptosis o muerte celular, como lo que se manifestó en el presente trabajo de investigación.

En las hojas los daños fueron notorios para ambos metales sobre todo en el parénquima asimilador o clorofilico y en la deformación de paredes de la epidermis tanto en haz como envés (Ernst et al., 1992); esto conlleva a que se presente por consiguiente limitación en la síntesis clorofílica destacándose las plantas hiperacumuladoras que pueden vivir en ambientes con altas concentraciones de nutrientes y agentes tóxicos por lo que se utilizan procesos de fitorremediación.

En los tallos aparecieron deformaciones de las células del parénquima de relleno esto se presentó probablemente por la intensa acumulación de plomo (Seregin e Ivanov, 1997). Según Verma y Dubey (2003), este metal se mueve predominantemente dentro del apoplasto de la raíz en una forma radial a través del cortex y se acumula próxima a la endodermis en la banda de Caspari, donde forma por consiguiente una contención tenue para que el plomo se movilice desde la raíz hacia las partes aéreas, resultado por consiguiente, alteración de los procesos fotosintéticos en el follaje. Yllanes et al. (2014), con bioensayos en plantas de maíz confirmo que existe inhibición en la tasa fotosintética a consecuencia de conllevar a un menor requerimiento de biosíntesis de clorofila, que para el caso del estrés con plomo en le vegetal ocasiona una disfunción en la absorción de algunos elementos esenciales como el magnesio o sustituye a este elemento en cada molécula de clorofila.

\section{CONCLUSIONES}

Los metales pesados Cadmio y Plomo resultaron tóxicos sobre las plantas de Brachiaria arrecta lo cual se traduce en alteraciones de características morfoanátomicas, se aprecia en deformaciones de tejidos en raíces, tallos y hojas, por consiguiente, este estrés metalífero suprime funciones básicas en esta planta como la nutrición, el transporte de nutrientes esenciales y fotosíntesis, la división celular y el crecimiento de los tejidos fundamentales. 
La toxicidad iónica con estos metales causó daño evidente en la ultraestructura de las raíces, lo que afecto los mecanismos específicos de la nutrición vegetal en función de absorber, translocar y acumular nutrientes necesarios para su metabolismo, por consiguiente las adaptaciones específicas de estas poaceas frente al estrés metalífero no presento los mecanismos de resistencia que redujeran la entrada en la planta de estos patógenos tóxicos, o una vez absorbidos permiten su almacenamiento en lugares no perjudiciales para las células.

Se encontró que las células son sensibles al daño de $\mathrm{Cd}^{2+}$ y $\mathrm{Pb}^{2+}$ por su estrecha relación interdependiente con otros cationes divalentes, lo que afecta por consiguiente las zonas cercanas a la endodermis, en los tallos en las células de relleno y en las hojas en el parénquima clorofílico. Por lo anterior, las plantas expuestas a este tipo de estrés abiótico redujeron su crecimiento principalmente por el bloqueo del $\mathrm{Pb}^{2+} \mathrm{y} \mathrm{Cd}^{2+}$, hacia los canales, principalmente los transportadores de $\mathrm{Ca}^{2+}$ componente fundamental de las paredes celulares de las raíces, ya que este catión se necesita para mantener la integridad de las membranas y el correcto funcionamiento del transporte selectivo de iones en condiciones mínimas, al existir bloqueo de elementos nutritivos y paso de metales pesados sin función biológica genera disfunciones que pueden conducir a una senescencia acelerada de las partes aéreas como el tallo y las hojas, y conllevar por consiguiente a una muerte de hojas maduras y jóvenes como se describió en el cuadro de síntomas crecientes.

\section{AGRADECIMIENTOS}

Al banco de anteproyectos de investigación científica o tecnológica de COLCIENCIAS convocatoria 503-2010 (COLCIENCIAS), por la confianza suministrada a los investigadores, y todo el personal auxiliar de las universidades de Pamplona y Nacional de Colombia, por el apoyo prestado.

\section{BIBLIOGRAFIA}

BHOPAL, R. 2008. Concepts of Epidemiology Integrating the ideas, theories, principles and methods of epidemiology (2nd edition).New York: Oxford University Press. 411 p.

BARCELÓ, J., POSCHENRIEDER, C., TOLRÀ, R.P. 2003. Importance of phenolics in rhizosphere and roots for plant metal relationships. pp. 15 - 19. In: G. Gobran (ed.) Extended Abstracts 7th ICOBTE Upsala. 62 - 163 p.

BOWIE S. y THORNTON, N. 1985: Environmental Geochemistry and Health. Kluwer Academic Publ., Hingham. MA. En: www.ehu.es/sem/ macla_pdf/macla10/Macla10_48.pdf; consulta: abril, 2014.

BROWN, E T. y HOCK, E. 1988. Discussion on paper 2043 by R. near entiled 'Determination $\mathrm{R}$. of shear failure envelope in rock massees'. J. Geotech. Engng. Dir., ASLE, 114. 3:371 - 373.

CANCHILA, E.R., SOCA, M., OJEDA, F., MACHADO, R y CANCHILA, N. 2010. Dinámica de crecimiento de 24 accesiones de Brachiaria spp. Pastos y Forrajes. 33(4):1 - 9.

COBB, G., SANDS, K., WATERS, M., WIXSON, M. y DORWARD-KING, E. 2009. Accumulation of heavy metals by vegetables grown in mine wastes. Environmental Toxicology and Chemistry. 19(3):600 - 607.

CHENG, H.M., ZHENG, C.R., TU, C. y ZHOU, D.M. 2001. Studies on loading capacity of agricultural soils for heavy metals and its applications in China. Applied Geochemistry. 16:1397 - 1403. 
DAVIES, B.E. 1995. Lead and other heavy metals in urban areas and consequences for the health of their inhabitants. In: Majumdar, S.K., Miller, E.W., Brenner, F.J. (eds), Environmental Contaminants, Ecosystems and Human Health, pp. 287-307. The Pennsylvania Academy of Science, Easton PA, USA.

DOCE. 2001. Reglamento CE 466/2001 de la Comisión por el que se fija el contenido máximo de determinados contaminantes en los productos alimenticios. DOCE, 16 marzo 2001 L77/1-13. Disponible en: http://www.boe.es/ doue/2001/077/L00001-00013.pdf, consulta: marzo, 2014.

ESPINOZA, F., LLINIMA, R. y VARGAS, M. 2013. Contaminación por plomo un enemigo silencioso. En: http://www.slideshare.net/ fespinoza02/contaminacin-por-plomo; consulta: junio, 2013.

ERNST, W., VERKLEIJ,J. y SCHAT, J.1992. Metal tolerance in plants. Acta Botanica Neerlandica. 41:229 - 248.

HUANG, JW., GRUNES, DL. y KOCHIAN LV. 1994. Voltage dependent Ca2+ influx into rightside-out plasma membrane vesicles isolated from wheat roots: characteristic of a putative $\mathrm{Ca} 2+$ channel. Proceedings of the National Academy of Sciences of the United States of America. 91(8):3473 - 3477.

HUANG, J. y CUNNINGHAM, S. 1996. Lead Phytoextraction: species variation in lead uptake and translocation. New Phytol. 134:75 - 84.

JARVIS, M. y LEUNG, D. 2002. Chelated lead transport in Pinus radiata: an ultrastructural study. Environmental and Experimental Botany. 48: 21 - 32.
MARSCHNER, H. 1995. Mineral Nutrition of Higher Plants. Ed 2. Academic Press, Londres. $862 \mathrm{p}$.

MARSCHNER,P.,GODBOLD,DL.yJUTSCHHE, G. 1996. Dynamics of lead accumulation in mycorrhizal Norway spruce (Piceaabies (L.) karst.). Plant Soil.178:239 - 245.

MARSHALL, J., CORZO, A., LEIGH, RA. y STANDERS, D. 1994. Membrane potential-dependent calcium transport in right-side-out plasma membrane vesicles from Zea mays L. roots. The Plant Journal. 5(5):683 - 694.

MERCER, E. y BIRBECK, M. 1974. Manual de microscopía electrónica para biólogos. Ed. Blume. Madrid. 118 p.

NASTAR, L. 2012. Inventario de bioindicadores ambientales de calidad de suelos, asociados al corredor pretolífero. Tesis de grado Bióloga. Universidad de Pamplona. 78 p.

OLIVERA, Y., MACHADO, R., DEL POZO, P.P., RAMÍREZ, J. y CEPERO, B. 2009. Evaluación agronómica de una asociación de 20 accesiones de Brachiaria brizantha con Stylosanthes guianensis CIAT-184. p. 96. En: Memorias. VIII Taller Internacional Silvopastoril «Los árboles y arbustos en la ganadería». EEPF «Indio Hatuey». Matanzas, Cuba. cd-rom.

PORTA, M. 2008. A Dictionary of Epidemiology (5th edition). New York: Oxford University Press. 289

PELÁEZ, M. 2014. Escala valorativa de reacciones crecientes de fitotoxicidad con metales pesados en $B$. radicans. Mimeografo. Resultado preliminar. Trabajo de grado:" Evaluación del estrés abiótico en Brachiarias pp. Inducido por bioacumulación de cadmio y plomo, en una zona aledaña 
al corredor Petrolífero de Barrancabermeja (Colombia), para optar al título Doctor en Ciencias Agropecuarias, Universidad Nacional de Colombia, Sede Palmira. 228 p.

RESH, H. 2001. Cultivos hidropónicos. Madrid Mundiprensa. 702 p.

ROMERO-PUERTAS, M.C., CORPAS, F.J., RODRÍGUEZ-SERRANO, M., GÓMEZ, M., DEL RÍO, L.A. y SANDALIO, L.M. 2007. Differential expression and regulation of antioxidative enzymes by cadmium in pea plants. Journal of Plant Physiology.164:1346 -1357.

SHANNON, J.G., NELSON, R.L. y WRATHER, J.A. 2010. Registration of LG04-6863 soybean germplasm line with diverse pedigree. Iournal of Plant Registrations. 4:70 - 72.

SÁNCHEZ, C. J. 2010. Metodologías analíticas para la determinación de metales tóxicos en muestras de interés ambiental. Tesis de Maestría, Universidad Nacional de Colombia. 76 p.

SÁNCHEZ, A., LÓPEZ, M. y NADAL, J. 2007. Bioaccumulation of lead, mercury, and cadmium in the greater hite-toothed shrew, Crocidurarussula, from the Ebro Delta (NE Spain): sex- and age-dependent variation. Environmental Pollution. 145(1):7 - 14 .

SEREGIN, I. y IVANIOV, V. 2001.Physiological aspects of cadmium and lead toxic effects on higher plants. Russian Journal of Plant Physiology. 48:606 - 630.

SIEGEL, F. R., 2002, Environmental geochemistry of potentially toxicmetals [M]: Springer-Verlag Berlin Heidelberg. 1 - 217 p.

VERMA, S. y DUBEY, R. 2003. Lead toxicity induces lipid peroxidation and alters the activities of antioxidant enzymes in growing rice plants. Plant Science. 164:645 - 655. 130.

WENG, L., TEMMINGHOFF, E. J. y VAN RIEMSDIJK, W. H. 2001. Contribution of individual sorbents to hecontrol of heavy metal activity in sandy soil. Environmental Science \& Technology. 35:4436 - 43.

YLLANES, P., VÉLEZ-AZAÑERO, A. y LOZANO, S. 2014. Phytotoxic effects of lead on dekalb hybrid maize (Zea mays L.) in sandy and silty soil. The Biologist. 12(2):337 - 348. 